Afr. J. Trad. CAM (2006) 3 (4): 23 - 33

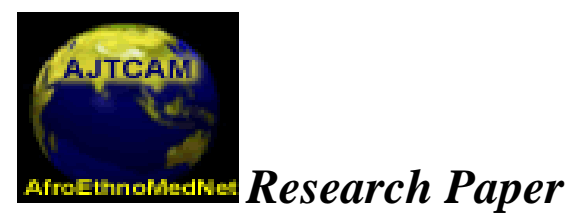

Afr. J. Traditional, Complementary and Alternative Medicines www.africanethnomedicines.net

ISSN 0189-6016@2006

\title{
EFFICACY OF STANDARDISED HERBAL EXTRACTS IN TYPE 1 DIABETES - AN EXPERIMENTAL STUDY
}

\author{
Sarika Jain, P. *Pandhi, A.P. Singh*, Samir Malhotra, \\ Department of Pharmacology, PGIMER, Chandigarh. \\ MD (Alternative Medicine), Ayurvedic Practitioner, Chandigarh. \\ E-mail: ppandhi17@hotmail.com, Tel: 0172-2747585, Ext: 5241, 5240
}

\begin{abstract}
In the present study, the hypoglycemic activity of Withania somnifera Dunal, Allium sativum Linn., Gymnema sylvestre (Retz.) Schult, Ferula foetida (Bunge.) Reg. and Murraya koenigii (L.) Spreng. extracts have been studied in an experimental model of type 1 diabetes. Type 1 diabetes was induced in albino rats by a single intraperitoneal injection of streptozotocin (60 mg/kg). Rats with fasting blood glucose (FBG) more than $250 \mathrm{mg} / \mathrm{dl}$, $72 \mathrm{~h}$ after STZ administration, were treated with extracts of above mentioned medicinal plants. The fasting blood glucose was determined every week for 3 weeks by the glucose oxidase method. STZ-administration led to a highly significant elevation in FBG levels. The percent decrease in FBG levels from STZ-induced hyperglycemia was $43.3 \pm 27.8$, $48.2 \pm 22.4$ and $48.2 \pm 7.9$, after 3 weeks of treatment with standardised extracts of Withania somnifera (1.5\% withanolides), Allium sativum (0.6\% allicin) and Gymnema sylvestre (75\% gymnemic acid), respectively. The fall in blood glucose with the herbal extracts was less when compared to insulin. In the vehicle treated group, there was $8.8 \pm$ 9.3 percent increase in blood glucose values at the third week of treatment and in insulin treated group, percent decrease in blood glucose from the values obtained at $72 \mathrm{~h}$ after STZ-administration was $63.5 \pm 4.9$. Ferula foetida ( $60 \%$ ferulic acid) and Murraya koenigii extracts did not show any hypoglycemic effect in animal model of type 1 diabetes.
\end{abstract}

Key words: Herbal extracts, Withania somnifera, Allium sativum, Gymnema sylvestre, Experimental type 1 diabetes.

\section{Introduction}

The prevalence of diabetes in India is estimated to be 1-5\% (Rao et al., 1989). Also, the number of diabetics is projected to rise from 15 million in 1995 to 57 million by the 


\section{Afr. J. Trad. CAM (2006) 3 (4): 23 - 33}

year 2025 making it the country with the highest number of diabetics in the world (King et al., 1998).

Although, insulin and oral hypoglycaemic agents are the mainstay of treatment of diabetes, they have prominent side effects and fail to alter the course of diabetic complications. The high cost of some agents and potential for adverse effects have led several investigators to focus their attention on the traditional medicines.

The World Health Organisation has estimated that a low income Indian family with a diabetic patient devotes $25 \%$ of the income to the care of that patient. One third of the diabetic patients take alternative medications that they consider efficacious (Ryan et al., 2001). Garlic, Echinacea, herbal mixtures and glucosamine are the most commonly used alternative medications.

According to ethno-botanical information, about 800 plants may possess antidiabetic potential (Alascon-Agmlara et al., 1998). Several of traditional plants have shown anti-diabetic potential, when assessed in experimental models of diabetes.

In India, indigenous remedies have been used in the treatment of diabetes mellitus since sixth century BC (Grover and Vats., 2001). There are several medicinal herbs used for the treatment of diabetes in Ayurvedic system of medicine. Withania somnifera Dunal (Solanaceae) is used as rejuvenator in Ayurvedic system of medicine. Modern investigations have demonstrated anti-stress (adaptogen) effect of Withania somnifera. Anti-stress drugs are useful in management of stress related disorders such as arthritis, hypertension, diabetes and general debility. Allium sativum Linn. (Liliaceae) is used as traditional remedy for diabetes. Gymnema sylvestre (Retz.) Schult (Asclepiadaceae) is traditional Ayurvedic remedy for the treatment of diabetes. Sushruta, the great Indian Surgeon described the herb as best medicinal agent for treating diabetes.

Ferula foetida (Bunge.) Reg. (Apiaceae) is used as antispasmodic in Ayurvedic system of medicine. It is part of list of promising medicinal plants targeted for antidiabetic research (Akhtar and Shah., 1993). Murraya koenigii (L.) Spreng. (Rutaceae) is a folk remedy for treating diabetes. Fine powder of fresh leaves is recommended on empty stomach in treating diabetes. Recent investigations have demonstrated hypoglycemic and antihyperglycemic activity of Murraya koenigii leaves in diabetic rats (Yadev et al., 2002). This study is aimed to prove or disprove the hypoglycemic potential of some of the Indian herbs by using the extracts containing quantified active ingredients (except Murraya koenigii where non-standardised extracts were used).

\section{Materials and Methods Chemicals}

Streptozotocin was obtained from Sigma Chemical Co. (USA). DPEC-GOD/POD kit for quantitative blood glucose determination was purchased from Ranbaxy Co. (INDIA). Insulin was purchased from Knoll Pharmaceuticals, Mumbai.

\section{Plant extracts}

Following extracts were used: 
Afr. J. Trad. CAM (2006) 3 (4): 23 - 33

a) Alcoholic extract of root of Withania somnifera Dunal. (Winter Cherry) containing $1.5 \%$ withanolides,

b) Alcoholic extract of bulb of Allium sativum Linn. (Garlic) containing $0.6 \%$ allicin $=$ 0.03 of allicin,

c) Alcoholic extract of leaves of Gymnema sylvestre R.Br. (Periploca of Woods) containing $70 \%$ of gymnemic acids,

d) Aqueous extract of oleoresin of Ferula foetida Linn. (Asafoetida) containing 60\% ferrulic acid including resinous substances, and

e) Extracts of leaves of Murraya koenigi Spreng. (Curry leaves) - hexane extract, chloroform extract, methanol extract and aqueous extract,

These extracts were tested for their efficacy in type 1 diabetes animal model and also, to compare their efficacy with insulin therapy. All extracts (except Murraya) were procured from Sanat Products, New Delhi. Before evaluation of Murraya koenigii, a sample was drawn for analysis. Considerable care was exercised to ensure that this sample was truly representative. Fresh leaves of Murraya koenigii were collected from vicinity of Chandigarh from a natural population. The plant was identified by Dr.A.S.Sandhu in the Department of Natural Products, National Institute of Pharmaceutical Education \& Research (NIPER) Mohali. A voucher specimen has been collected for the herbarium of the institute.

Murraya extract was prepared in the laboratory from M. koenigi leaves by soxhlet extraction procedure using solvents of increasing polarity in succession; hexane, chloroform, methanol. Aqueous extract of Murraya leaves was prepared by maceration. Following active principles were possibly present in the different fractions of Murraya extracts:

\begin{tabular}{|l|l|}
\hline Solvent used for extraction & \multicolumn{1}{c|}{ Active principles extracted } \\
\hline Hexane & Triterpenes, fatty acids, steroids, amino acids \\
\hline Chloroform & Alkaloids, other amine like compounds \\
\hline Methanol & Carbohydrates, alkaloids and glycosides \\
\hline Water & Mono-saccharides, saponins. \\
\hline
\end{tabular}

Withania, Garlic, Asafoetida, Gymnema and Murraya aqueous extracts were dissolved in normal saline; hexane, chloroform and methanol fractions of Murraya were dissolved in dimethyl sulfoxide (DMSO).

Withania (20 mg/kg), Garlic (100 mg/kg), Gymnema (100 mg/kg), Asafoetida (100 or $200 \mathrm{mg} / \mathrm{kg}$ ) and Murraya $(200 \mathrm{mg} / \mathrm{kg}$ ) extracts were administered to diabetic rats intraperitoneally once daily. Insulin was administered subcutaneously daily in a dose of 5 $\mathrm{U} / \mathrm{kg}$.

\section{Animal Experiments}

Sprague Dawley rats of either sex weighing 150-200 g were housed in an airconditioned room on a 12 - hour light/dark cycle at $21 \pm 3^{\circ} \mathrm{C}$ and supplied with standard pellet diet and tap water ad libitum. Procedures involving animals and their care were 


\section{Afr. J. Trad. CAM (2006) 3 (4): 23 - 33}

conducted in conformity with the guidelines of the institute animal ethics committee, which also approved the study.

The animals were randomly divided into six experimental groups; vehicle-treated diabetic control group, Withania extract treated diabetic rats, garlic extract treated diabetic rats, Gymnema extract treated diabetic rats, Asafoetida extract treated diabetic rats, Murraya fractions (hexane, chloroform, methanol or aqueous fraction) treated diabetic rats, and insulin treated diabetic rats. Each group had six animals.

All the above treatments were made for three weeks. Blood glucose determinations were performed in overnight fasted rats at first, second and third weeks of the treatments.

\section{Induction of Type 1 Diabetes}

Experimental type 1 diabetes was induced by a single intraperitoneal injection of STZ to animals fasted overnight at a dose of $60 \mathrm{mg} / \mathrm{kg}$ body weight (fresh solution in $0.1 \mathrm{~N}$ citrate buffer, $\mathrm{pH}$ 7.5) (Suresh Babu and Srinivasan., 1998). The rats had free access to 5\% of glucose water and basal diet ad libitum during the next 24 hours. Blood samples were obtained from retroorbital plexus in STZ injected animals at $72 \mathrm{~h}$, after an overnight fast. Fasting blood glucose levels were determined by glucose oxidase method (Huggert and Dixon., 1957). Rats with fasting blood glucose levels above $250 \mathrm{mg} / \mathrm{dl}$ were used as diabetic animals.

\section{Statistical Analysis}

Percent decrease in blood glucose level from diabetic values (72 h after STZadministration) was calculated as:

Diabetic blood glucose-blood glucose after treatment

\section{Diabetic blood glucose}

Data was presented as mean \pm SE. Baseline values were compared with treatment values and the inter-group comparisons were also made. Differences between groups were calculated using one-way ANOVA supplemented with Dunnett's ' $t$ ' test. A paired student's ' $t$ ' test was applied to the data for evaluation of differences between pre- and post- treatment values. $\mathrm{P}$ value $<0.05$ was considered to be statistically significant.

\section{Results \\ Control group}

The normal (baseline) blood glucose values of the rat were $69.89 \pm 8.9 \mathrm{mg} / \mathrm{dl}$. Fasting blood glucose levels, $72 \mathrm{~h}$ after STZ injection were $290.4 \pm 13.2 \mathrm{mg} / \mathrm{dl}$ and thereafter, at 1, 2 and 3 weeks of vehicle administration were found to be $300.9 \pm 9,311 \pm$ 10.4 and $316.2 \pm 10.2 \mathrm{mg} / \mathrm{dl}$, respectively. Though the blood glucose was rising every week but the rise was not statistically significant as compared to diabetic glucose values.

Percent increase in blood glucose from baseline at 72 h, 1, 2 and 3 week after STZ treatment were $315.51 \pm 6.7,330.53 \pm 4.7,344.98 \pm 5.9$ and $352.42 \pm 8.6$ respectively. 
Afr. J. Trad. CAM (2006) 3 (4): 23 - 33

\section{Withania group}

With Withania extract treatment, the blood glucose was progressively lowered at 1 , 2 and 3 week (226 \pm 15.9, $196.3 \pm 19.5$ and $163.5 \pm 25.6 \mathrm{mg} / \mathrm{dl})$ This decrease in blood glucose was statistically significant as compared to control group and insulin treated rats at 2 and 3 week but was not significantly different from insulin treated rats at 1 week (Figure 1).

There was a statistically significant decrease in blood glucose levels (\%) from diabetic levels i.e. $21.4 \pm 17.1,31.9 \pm 22.2$ and $43.3 \pm 27.8$ at 1,2 and 3 weeks of Withania treatment.

\section{Garlic group}

Administration of alcoholic extract of A. sativum to diabetic rats with blood glucose $282.1 \pm 6.2 \mathrm{mg} / \mathrm{dl}$, attenuated the hyperglycemia induced by STZ significantly. The fasting blood glucose at 1, 2 and 3 week of garlic administration was $226.8 \pm 12.8$ $\mathrm{mg} / \mathrm{dl}, 178.55 \mathrm{mg} / \mathrm{dl}$ and $143.5 \pm 15.6 \mathrm{mg} / \mathrm{dl}$ respectively (Table 1). The decrease in FBG with garlic was statistically significant at 1, 2 and 3 week as compared to control group, and was also significantly different from insulin group, except at 1 week interval (Figure 2).

A progressive percent decrease in FBG from diabetic blood glucose was observed with garlic treatment, the values being 19.6 \pm 10.9 , $35.4 \pm 11.5$ and $48.2 \pm 22.4$ at 1 , 2 and 3 week of treatment, which was significant versus control group and insulin group.

\section{Gymnema group}

STZ induced hyperglycemia (281.1 $\pm 6.6 \mathrm{mg} / \mathrm{dl})$ was significantly and progressively decreased with extract treatment $(233.5 \pm 3.3 \mathrm{mg} / \mathrm{dl}, 192.6 \pm 9.9 \mathrm{mg} / \mathrm{dl}$ and $150.3 \pm 7.6 \mathrm{mg} / \mathrm{dl}$ at 1,2 , and 3 week of treatment) (Figure 3).

Percent decrease in blood glucose at various time intervals of treatment from diabetic values with treatment was $16.9 \pm 4.9$, $31.4 \pm 14.8$ and $48.2 \pm 7.9$, which was statistically significantly, but was less than insulin.

\section{Asafoetida group}

Hyperglycaemia induced by STZ was not different in all the groups, it was $290.4 \pm$ $13.2 \mathrm{mg} / \mathrm{dl}$ in control group, $293.9 \pm 5.3 \mathrm{mg} / \mathrm{dl}$ in Asafoetida $(100 \mathrm{mg} / \mathrm{kg}), 293 \pm 2.3 \mathrm{mg} / \mathrm{dl}$ in Asafoetida (200 mg/kg) and $283.1 \pm 16.1 \mathrm{mg} / \mathrm{dl}$ in insulin group.

Administration of Asafoetida at two doses $100 \mathrm{mg} / \mathrm{kg}$ and $200 \mathrm{mg} / \mathrm{kg}$ could not decrease the FBG levels, rather the FBG was significantly increased at 3 weeks from baseline i.e. $340.4 \pm 1.2 \mathrm{mg} / \mathrm{dl}$ in asafoetida $100 \mathrm{mg} / \mathrm{kg}$ and $341 \pm 10.5 \mathrm{mg} / \mathrm{dl}$ in asafoetida $200 \mathrm{mg} / \mathrm{kg}$ groups as compared to $316.2 \pm 10.2 \mathrm{mg} / \mathrm{dl}$ in control group (Figure 4).

The percent increase in FBG from blood glucose levels $72 \mathrm{~h}$ after STZadministration was $10.8 \pm 6.2,15.4 \pm 7.1$ and $19.5 \pm 8.7$ in asafoetida.100 group and $10.7 \pm$ 8.9, 
Afr. J. Trad. CAM (2006) 3 (4): 23 - 33

$14.4 \pm 9$ and $15.2 \pm 10.7$ in Ferula foetida 200 group, at the first, second and third week of treatments which is not dissimilar when compared to control group, but were highly significant when compared to insulin treated rats.

\section{Murraya group}

Four fractions of Murraya koenigii extract (hexane, chloroform, methanol and aqueous) were administered to the different groups of rats. None of the four extracts reduced the hyperglycemia induced by STZ. The FBG values at different time intervals of treatment were not statistically different from the control group (Figure 5).

The percent change in FBG from that obtained 72h after STZ- administration was $6.7 \pm 8,-8.1 \pm 8.5,-11.3 \pm 9$ in M. koenigii (hexane) group; - $3.9 \pm 5.6,-6.6 \pm 6.2$ and $12.5 \pm 14.9$ in M. koenigi (chloroform) group; $-5 \pm 3.6,-7.4 \pm 5.2$ and $-10.7 \pm 6$ in $\mathrm{M}$. koenigi (methanol) group and $-3.2 \pm 2.3,-6.5 \pm 5.7$ and $-8.3 \pm 5.2$ in M. koenigi (aqueous) group at first, second and third weeks of treatment correspondingly, indicating increase in FBG from baseline but not statistically significant when compared to values $72 \mathrm{~h}$ after STZ- administration as well as control group at corresponding time intervals.

\section{Insulin group}

The fasting blood glucose after STZ - injection (283.1 $\pm 16.1 \mathrm{mg} / \mathrm{dl})$ was tremendously decreased with insulin treatment to $215.6 \mathrm{mg} / \mathrm{dl}, 148.9 \mathrm{mg} / \mathrm{dl}$ and $100.3 \pm 7.8$ $\mathrm{mg} / \mathrm{dl}$ at 1,2 and 3 weeks of insulin treatment respectively. This decrease was highly significant in comparison to control group (Table 1).

The percent decrease in blood glucose levels from diabetic values in insulin treated rats was $23.9 \pm 6.8,47.4 \pm 8.6$ and $63.5 \pm 4.9$ at 1,2 and 3 weeks of treatment, respectively.

\section{Discussion}

Plants are a potential source of many drugs used in modern medicine, for example, quinine, opium alkaloids, paclitaxel, atropine, cardiac glycosides (digitalis, ouabain) and many more. Even the discovery of widely used anti-diabetic drug metformin was from the traditional approach of using Galega officinalis. But still the herbs as medicines have not gained enough momentum in scientific community. One of the factors for this is the lack of specific standards

being prescribed for herbal medicines (Gupta., 1994). In the present study, the main emphasis was laid on the use of standardized herbal extracts containing a quantified amount of active principle.

In the present study, the standardised extract of Withania somnifera has shown prominent hypoglycemic effect in STZ-treated diabetic rats. In a study, Trasina (an Ayurvedic polyherbal formulation containing Withania somnifera, Tinospora cordifolia, Eclipta alba, Ocimum sanctum, Picrorrhiza kurroa and shilajit) induced a dose related 


\section{Afr. J. Trad. CAM (2006) 3 (4): 23 - 33}

decrease in STZ-induced hyperglycemia and attenuation of STZ-induced decrease in islet superoxide dismutase SOD activity (Bhattacharya et al., 1997). This it can be concluded that standardised extract of Withania somnifera or combination with other herbs has prominent hypoglycemic effect. But at the same time it is warranted that in poly-herbal formulations like Trasina, the hypoglycaemic activity can not be alone attributed to Withania somnifera. Antioxidant property of shilajit, Withania somnifera and Picrorrhiza kurrao may be responsible for hypoglycemic effect. In this study, it was not clear which of the specific herb was accountable for the hypoglycaemic effect. Our study indicates that Withania somnifera alone is capable of lowering blood glucose in type 1 diabetes model. It has been observed that pancreatic islet cells possess very low levels of free radicals scavenging enzymes, including superoxide dismutase and are therefore, vulnerable to free radical toxicity (Mason and Chingnell., 1981). STZ-induced cytotoxicity of islets is reduced by SOD, considered to be the first cellular defense against superoxide radical toxicity (Grankvist et al., 1981). STZ-induced hyperglycemia in rats was significantly attenuated by standardised extract of Allium sativum, but the effect seen was less than that of insulin. An earlier study showed that oral administration of ethanol, petroleum ether and ethyl ether extracts of Allium sativum (dose $0.25 \mathrm{~g} / \mathrm{kg}$ ) caused 18.9, 17.9 and 26.2\% reduction in blood sugar in alloxan-diabetic rats, respectively (Jain and Vyas., 1975). In another study oral administration of $0.25 \mathrm{~g} / \mathrm{kg}$ allicin produced hypoglycemia comparable to tolbutamide in mildly diabetic rabbits (glucose levels ranging from 180 to $300 \mathrm{mg} \%$ ) while it showed no effect in severely diabetic animals (blood sugar > $350 \mathrm{mg} \%$ ) (Mathew and Augusti., 1973). Similar results were observed in our study, that the efficacy of garlic declined from the second through the third weeks of the study. This may be attributed to the fact that STZ-induced hyperglycemia progressively increased with time.

Allicin is the chief sulfur containing principle of garlic. It combines readily with compounds containing - SH groups (Skinner., 1955; Stoll and Juckes., 1955), like cysteine, glutathione and serum albumin fractions, which combine with insulin and inactivate it; hence sparing the already available endogenous insulin from degradation. This may be probable mechanism of action of allicin.

Results of the present study demonstrate that standardised extract of Gymnema sylvestre significantly decreased the blood glucose levels progressively at every week of treatment in type 1 diabetes model. Earlier studies have also demonstrated the hypoglycemic effect of this herb. Dried leaf powder of Gymnema sylvestre, when given to alloxanized rabbits, led to antihyperglycemic effect alongwith decrease in activity of gluconeogenic enzymes and reversal of pathological changes in liver initiated during the hypoglycemic phase (Shanmugasundaram et al., 1983). Oral administration of aqueous extract of leaves of Gymnema sylvestre for 20-60 days normalized blood sugar levels of STZ-diabetic rats through $\beta$-cell regeneration (Shanmugasundaram et al., 1990). Single as well as chronic (32-35 days) oral administration of aqueous extract of G. sylvestre leaves to $18 \mathrm{~h}$ fasted non-diabetic and STZ-induced mildly diabetic rats showed significant reduction in blood glucose on OGTT without any significant effect on immuno-reactive insulin levels (Okabayashi et al., 1990). Oral administration of varying doses (50, 100, 200 and $500 \mathrm{mg} / \mathrm{kg}$ ) of aqueous extract to normal and STZ-diabetic rats showed significant 


\section{Afr. J. Trad. CAM (2006) 3 (4): 23 - 33}

dose-dependent hypoglycemic action of sylvestre leaves extract for seven days on insulin resistance in STZ-diabetic rats (Taminaga et al., 1995).

The hypoglycemic principles of Gymnema sylvestre isolated from the saponin fraction of the plant are referred as gymnemosides and gymnemic acids (Murakani et al., 1996; Yoshikawa et al., 1997). Triterpene glycosides isolated from the plant inhibited glucose utilization in muscle (Shimizu et al., 1996). Gynmemic acid fraction has been shown to inhibit glucose uptake in intestine (Shimizu et al., 1997). Alcoholic extract of Gymnema sylvestre also stimulates insulin secretion from the rat islet of Langerhans and several pancreatic $\beta$-cell lines in absence of other stimuli (Persaud et al., 1999). Among the four gymnemic acids, gymnemic acid I lacked antihyperglycemic effect (Yoshikawa et al., 1997), suggesting that gymnemic acids II, III, IV could have been responsible for the effects seen in our study.

Gymnemic acids appear to be effective in type 1 diabetes model by virtue of their effect on pancreatic $\beta$-cells to stimulate insulin secretion and, on intestine to inhibit glucose uptake.

An extract comprising of Nigella sativa, Myrrh, Gum olibanum, Gum asafoetida and aloe was administrated to STZ-diabetic rats (Al-Awadi et al., 1991). The plant mixture had a blood glucose lowering effect, which was shown to be partly mediated through decreased hepatic gluconeogenesis. It has been postulated that the extract may prove to be useful in the treatment of type 2 diabetes. Since, it is not clear, how much of this activity can be ascribed to asafoetida, we investigated if Ferula foetida alone, a common condiment in Indian meals have any such effect. Our results in type 1 diabetes model were negative suggesting no action of asafoetida in insulin deficiency.

In an earlier study, it was observed that oral feeding of Murraya koenigii leaves diet $(10 \% \mathrm{w} / \mathrm{v})$ for 60 days to normal rats resulted in hypoglycaemia associated with increased hepatic glycogen contents due to increased glycogenesis and decreased glycogenolysis and gluconeogenesis (Khan et al., 1995). Dietary supplementation with curry leaves have been shown to increase lecithin cholesterol acyltransferase activity (Khan et al., 1996).

Earlier studies were conducted using leaf powder, but we used the extracts of Murraya leaves extracted with solvents of different polarity so as to capture all possible active constituents in the extract, which appears to be a better approach. In the present study, none of the Murraya extracts was able to lower the blood glucose raised by STZadministration.

Several experimental and clinical studies have earlier shown the efficacy of herbs in diabetes. However, they had serious limitations. Most of the studies have used either a part of plant or its powder for administration. Clinical studies conducted have mostly used small sample size and inappropriate controls. So, the information about the effect of a particular phyto-constituent from the herb in animal model of type 1- diabetes was lacking. Therefore, we have investigated the effect of standardized plant extracts in STZ-induced hyperglycemia, a proven model of type 1 diabetes.

This study demonstrates the efficacy of standardised extracts of Withania somnifera, Allium sativum and Gymnema sylvestre in type 1 diabetes model, though not at par with insulin that is the standard conventional therapy for type 1 diabetes. 


\section{Afr. J. Trad. CAM (2006) 3 (4): 23 - 33}

This study raised several questions pertinent to the clinical use of herbs as antidiabetic agents, for instance, whether these herbs can be used as monotherapy or addon therapy in diabetes management. Secondly, their indiscriminate use by the patients may lead to possibility of hypoglycemia. Thirdly, both experimental and clinical studies to elucidate the mechanism of action of herbs demonstrated to be efficacious need to be conducted. Also, randomized controlled clinical trials are required to prove the safety and efficacy of these herbs in diabetic patients.

\section{Acknowledgement}

We are highly thankful to Dr.A. S. Sandhu scientist, NIPER, Mohali for his botanical expertise. We also extend sincere thanks to Sanat Products for supplying standardised herbal extracts.

\section{References}

1. Akhtar, M. S. and Shah, M. V. (1993). Elemental constituents of antidiabetic screening of a folklore medicinal plant prescription. Ind J Toxicology, Occupational and Envt Health; 2 (1): 46.

2. Alarcon - Aguilara, FJ., Roman-Ramos, R., Pesez-Gutierrez, S., Aguilar-Contreras, A., Contreras-Weber, C. and Flores-Saeuz, J.L. (1998). Study of the anti-hyperglycemic effect of plants used as antidiabetics. J. Ethnopharmacol. 61, $101-110$.

3. Al-Awadi, F., Fatania, H. and Shamte, U. (1991). The effect of a plants mixture extract on liver gluconeogenesis in streptozotocin induced diabetic rats. Diabetes Research 18, 163-168.

4. Anonymous. Indian Herbal Pharmacopoeia Volume 1. Worli, Mumbai: Indian Drug Manufacturers Association, 1998.

5. Anonymous. PDR for Herbal Remedies First Edition. Montvale, New Jersey: Medical Economics Company, 2001.

6. Barclay, T. S., Tsourounis, C. and McCart, G. M. (1998). Glucosamine. The Annals of Pharmacotherapy. 32:574-79.

7. Bhattacharya, S. K., Satyan, K. S., Chakrabarti, A., (1997). Effect of Trasina, an Ayurvedic herbal formulation, on pancreatic islet superoxide dismutase activity in hyperglycemic rats. Indian J. Experimental Biol. 35: 297-299.

8. Dorn, M., Knick, E. and Lewith, G. (1997). Placebo-controlled, double-blind study of Echinaceae pallidae radix in upper respiratory infections. Complement Ther Med. 5:40-42.

9. Grankvist., Marklund, S. and Taljedal, I. B., (1981). Superoxide dismutase is a prophylactic agent against alloxan diabetes..Nature 294: 158-160.

10. Grover, J. K. and Vats, V., (2001). Shifting Paradigm "From conventional to alternative medicine.” An introduction on traditional Indian medicine. Asia Pacific Biotechnology News 5 (1): 28-32.

11. Gupta, S. S., (1994). Prospects and perspectives of Natural products in medicine. Indian Journal of Pharmacology 26: 1-12. 
Afr. J. Trad. CAM (2006) 3 (4): 23 - 33

12. Huggert, A.S.G. and Nixon, DA., (1957). Use of glucose oxidase, peroxidase and odianisidine in determination of blood glucose and urinary glucose. Lancet 273: 368370.

13. Jain, R. C. and Vyas, C. R., (1975). Garlic in alloxan - induced diabetic rabbits. American Journal of Clinical Nutrition 28: 684 - 685 .

14. Khan, B. A. Abraham, A. and Leelamma, S. (1996). Biochemical response in rats to the addition of curry leaf (Murraya koenigi) and mustard seeds (Brassica juncea) to the diet. Plant Food Human Nutrition 49: 295 - 299.

15. Khan, B. A., Abraham, A. and Leelamma, S. (1995). Hypoglycaemic action of Murraya koenigi (curry leaf) and Brassica juncea (mustard): mechanism of action. Indian J. Biochem. Biophysics 32: 106 - 108.

16. King, H., Aubert, R. E. and Herman, W. H., (1998). Global burden of diabetes (1995 2025). Prevalence, numerical estimates and projections. Diabetes Care 21: 1414 1431.

17. Koch, H. P. and Lawson, L. D. (1996).. Garlic: The Science and Therapeutic Application of Allium sativum Linn. and Related Species, 2d ed. Baltimore: Williams and Wilkins, pp 62-64.

18. Mason, R. P. and Chingnell, C. F., (1981). Free radicals in pharmacology and toxicology- selected topics. Pharmacological Reviews 33: 189-211.

19. Mathew, P. T. and Augusti, K. T., (1973). Studies on the effect of allicin (diallyl disulfide-oxide) on alloxan diabetes. Hypoglycemic action and enhancement of serum insulin effect and glycogen synthesis. Indian Journal of Biochemistry and Biophysics 10: $209-212$.

20. Mhasker, K. S. and Caius, J. F. (1930). A study of Indian medicinal plants. II. Gymnema sylvestre R.Br. Indian J Med Res Memoirs. 16:72-75.

21. Murakami, N., Murakani, T., Kadoya, M., Matsuda, H; Yamahar, J. and Yoshikawa, M. (1996). New hypoglycemic constituents in gymnemic acid from Gymnema sylvestre. Chemical and Pharmaceutical Bulletin (Tokyo) 44: 469 - 471.

22. Okabayashi, Y., Tani, S. and Fujisawa, T., (1990). Effect of Gymnema sylvestre, R.Br. on glucose homeostasis in rats. Diabetes Research and Clinical Pactice 9: 143 - 148.

23. Persaud, S. J., Al-majed, H., Raman, A. and Jones, P. M., (1999). Gymnema sylvestre stimulates insulin release in vitro by increased membrane permeability. J. Ethnopharmacol. 163: 207 - 212.

24. Rao, P. V., Ushabala, P., Seshiah, V., Ahuja, M.M. and Mather, H.M. (1989). The Eluru survey: prevalence of known diabetes in a rural Indian population. Diabetes Research and Clinical Practice 7: 29 - 31.

25. Ryan, E. A., Pick, M. E. and Marceau, C. (2001). Use of alternative medicines in diabetes mellitus. Diabetes Medicine 18: 242 -245.

26. Shanmugasundaram, E. R. B., Gopinath, K. L., Shanmugasundaram, K. R. and Rajendran, VM., (1990). Possible regeneration of the islets of langerhans in streptozotocin-diabetic rats given Gymnena sylvestre leaf extracts. J. Ethnopharmacol. 30: 265-79. 
Afr. J. Trad. CAM (2006) 3 (4): 23 - 33

27. Shanmugasundaram, K. R., Panneerselvam, C., Samudram, P. and Shanmugasundaram, E. R. (1983). Enzyme changes and glucose utilization in diabetic rabbits: the effect of Gymnema sylvestre. J. Ethnopharmacol. 7: 205 - 234.

28. Shimizu, K., , Abe, T., Nakayyo, S., Urakawa, N., Atsuchi, M. and Yamashita, C. (1996). Inhibitory effects of glucose utilization by gymnemic acids in the guinea- pig ideal longitudinal muscle. J. Smooth Muscle Res. 32: 219 - 228.

29. Shimizu, K., Ozeki., M., Tanaka, K., Itoh, K., Nakayyo, S., Uratawa, N. and Atsuchi, M.(1997). Suppression of glucose absorption by some fractions extracted from Gymnema sylvestre leaves. The Journal of the Veterinary Medical Sciences 59 (4): 245 -251 .

30. Skinner, F. A. (1955). 'Modern methods of plant analysis'. Vol. III, Paech K and Tracey MV eds, Springer - Verlog, Berlin, 657-659.

31. Stoll, A., Jucker, E., (1955). Modern methods of plant analysis Vol. IV, Paech K and Tracey MVeds, Springer - Verlog, Berlin, 696-700.

32. Suresh Babu, P. and Srinivasan, K., (1998). Amelioration of renal lesions associated with diabetes by dietary curcumin in streptozotocin diabetic rats. Mol. Cell. Biochem. 181: 87-96.

33. Tominaga, M., Kimura, M. and Sugiama, K., (1995). Effects of seishin-renshi and Gymnema sylvestre on insulin resistance in streptozotocin - induced diabetic rats. Diabetes Res. Clinical Pactice 29: $11-17$.

34. WHO (1980). Expert committee on Diabetes Mellitus Second report. Technical report series 646. World Health Organisation Geneva.1980: 61-68.

35. Yadev, S., Tats, V., Dunnoo, Y. and Grover, J.K. (2002). Hypoglycaemic and antihyperglycemic activity of Murraya koenigii leaves in diabetic rats. PJ. Ethnopharmacol.P 82(2-3):111-116.

36. Yoshikawa, M., Murakami, T. and Kadoya, M., (1997). Medicinal food stuffs. IX. The inhibitors of glucose absorption from the leaves of Gymnema sylvestre $\mathrm{R}$. Br. (Asclepiadaceae): Structures of gymnemosides a and b. Chemical Pharmaceutical Bulletin (Tokyo) 45: 1671-1676.

37. Yoshikawa, M., Murakami, T. and Matsuda, H., (1997). Medicinal food stuffs X. Structures of new triterpene glycosides, gymnemosides -c, -d, -e and -f, from the leaves of Gymnema sylvestre R. Br.: influence of Gymnema glycosides on glucose uptake in rat small intestinal fragments. Chemical pharmaceutical Bulletin (Tokyo) 45: 2034-2038. 